\title{
Zinc-Catalyzed Synthesis of Conjugated Dienoates via Unusual Cross-Couplings of Zinc Carbenes with Diazo Compounds
}

\author{
Sergio Mata, ${ }^{[\mathrm{a}]}$ María J. González, ${ }^{[\mathrm{a}]}$ Jesús González, ${ }^{[\mathrm{a}]}{ }_{\text {Luis A. López }}{ }^{[\mathrm{a}] \star}$ and Rubén Vicente ${ }^{[\mathrm{a}] *}$ \\ In Memory of our inspiring mentor Prof. Dr. José Barluenga.
}

\begin{abstract}
Zinc-catalyzed selective cross-coupling of two carbene sources such as vinyl diazo compounds and enynones, enabled the synthesis of conjugated dienoate derivatives. This reaction involved the unprecedented coupling of a zinc furyl carbene with vinyl diazo compounds through the $\gamma$-carbon. Alternatively, dienoates were also prepared by a commutative cross-coupling of zinc vinyl carbenes generated from cyclopropenes and simple diazo compounds.
\end{abstract}

Assembling the two carbon fragments is the most convergent method to prepare highly substituted alkenes. Emblematic transformations such as Wittig or metathesis reactions are firstly considered when preparing alkenes. A different approach comprises the use of diazo compounds, which can be joined via carbene coupling. This archetypal reactivity of diazo compounds did not found a widespread applicability due to the difficulty to control homodimerization vs cross-coupling processes to prepare unsymmetrically substituted alkenes (Scheme 1, a). ${ }^{[1-3]}$ In spite of this difficulty, a few remarkable examples of Rh- and Au-catalyzed cross-couplings with diazo compounds have been recently reported by Davies ${ }^{[3 a]}$ and Sun. ${ }^{[3 b]}$ Similarly, crosscouplings between diazo compounds and a metal-carbene intermediates generated from a different source enable the preparation of challenging unsymmetrical alkenes. Again, governing homo- vs cross-coupling is awkward (Scheme 1, a) ${ }^{[4]}$ Examples of alkene synthesis by this approach were reported by Barluenga and Dixneuf using Fischer carbenes or propargylic esters as carbene partner in $\mathrm{Cu}^{\left[{ }^{[4--c]}\right.}$ or Ru-catalyzed ${ }^{[4 \mathrm{~d}]}$ crosscouplings with diazo compounds. In this context, we have recently been interested in the generation and subsequent trapping of zinc 2-furyl carbenes from conjugated enynones and inexpensive, low-toxic $\mathrm{ZnCl}_{2}{ }^{[5]}$ Since zinc salts do not promote $\mathrm{N}_{2}$-extrusion in stabilized diazo compounds, ${ }^{[6]}$ we reasoned that they could act as nucleophiles to trap the electrophilic zinc carbenes, ${ }^{[7]}$ avoiding undesired homocoupling processes. In this manner, we described the synthesis of functionalized alkenes, namely $\beta$-furylacrylates, by cross-coupling of enynones with stabilized diazo compounds (Scheme $1, b){ }^{[8]}$

Besides, the synthesis of 1,3-dienes is a relevant goal in chemistry due to the wide range of synthetic applications and the properties of this class of compounds. ${ }^{[9]}$ In view of this feature, we wondered if applying our previously described

[a] Jesús González, María J. González, Sergio Mata, Dr. Luis A. López and Rubén Vicente

Departamento de Química Orgánica e Inorgánica e Instituto

Universitario de Química Organometálica "Enrique Moles"

Universidad de Oviedo

c/ Julián Clavería 8, 33007, Oviedo (Spain).

E-mail: lalg@uniovi.es, vicenteruben@uniovi.es

Supporting information for this article is given via a link at the end of the document.((Please delete this text if not appropriate)) methodology, ${ }^{[8]}$ extended $\pi$-conjugated systems might be available by using the corresponding vinyl diazo compounds. Herein, we disclose our findings.

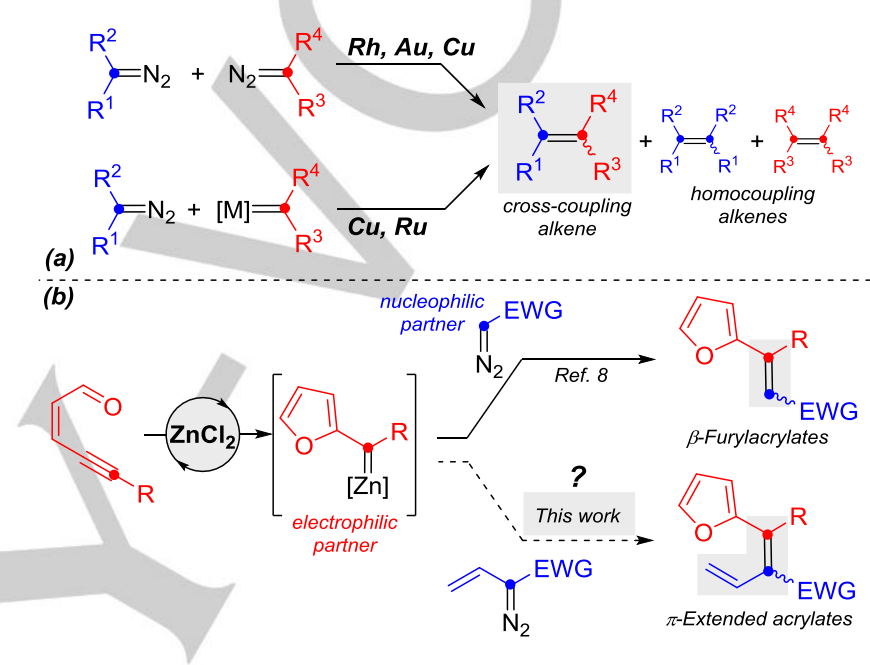

Scheme 1. (a) Synthesis of unsymmetrical alkenes by means of carbene coupling. (b) $\mathrm{ZnCl}_{2}$-catalyzed cross-coupling of enynones with diazo compounds.

Conjugated enynone 1a and ethyl 2-diazobut-3-enoate (2a) were selected at the outset (Scheme 2, a). Under previously optimized reaction conditions $\left(10.0 \mathrm{~mol} \%\right.$ of $\mathrm{ZnCl}_{2}, 1.2$ equiv. of 2a in $\mathrm{CH}_{2} \mathrm{Cl}_{2}$ at ambient temperature) ${ }^{[8]}$ the formation of a new penta-2,4-dienoate $\mathbf{3 a}$ arising from the cross-coupling of $\mathbf{1 a}$ and 2a was observed in a $71 \%$ isolated yield as a mixture of isomers $((2 E, 4 E):(2 Z, 4 Z):(2 Z, 4 E)=1: 1 \cdot 6: 2.7)$. Importantly, NMR analysis of 3 a clearly revealed that the formation of a new double bond took place at $\gamma$-position (green dot) of the vinyl diazo moiety. To our knowledge, this selectivity in cross-coupling reactions with vinyl diazo compounds is unprecedented, since in previous examples the alkene formation involved the participation of the $\alpha$-carbon (blue dot) (Scheme 2, b). ${ }^{[3 a-b, 10,11]}$ In view of this remarkable differential reactivity, we consequently attempted an optimization of the process. Indeed, by using 3.0 equiv. of $\mathbf{2 a}$, compound $3 \mathbf{a}$ could be obtained in $83 \%$ isolated yield and with near complete 2Z-selectivity and moderate $4 Z / 4 E$ selectivity $(4 Z: 4 E=2: 1) .{ }^{[12]}$ 


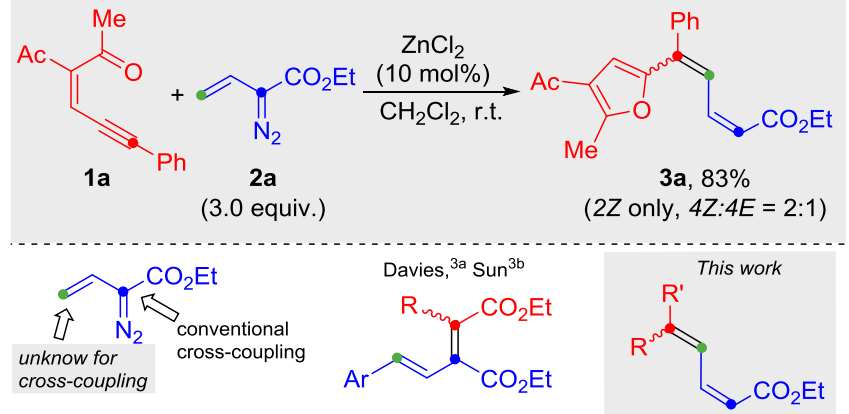

Scheme 2. Zinc-catalyzed cross-coupling of enynone 1a with vinyl diazo compound 2a (top) and comparison of positional selectivities (bottom).

The scope was subsequently evaluated by using conditions depicted in Scheme 2. These conditions led to an improved yield and Z/E better selectivity, which further facilitated analysis and purification processes. The scope is shown in Table 1. Enynones bearing aryl substituens as $\mathrm{R}^{3}$ group were converted into the corresponding dienoate derivatives 3 a-d in good yields. Importantly, both electron-rich and -poor arenes participated in the reaction. Moreover, ortho substitution was tolerated as well. Regarding the selectivity, compounds 3a-d were obtained with almost complete $2 Z$ selectivity, yet as $4 Z / 4 E$ mixtures. Similarly, enynones substituted with primary alkyl groups afforded compounds $3 \mathrm{e}-\mathrm{g}$ in reasonable yields $(2 Z, 4 Z / E$ mixtures). Interestingly, the use of a cyclopropyl-substituted enynone led to the formation of $3 \mathrm{~h}$ in a moderate $62 \%$ yield but with a remarkable high selectivity (20 mol\% of $\mathrm{ZnCl}_{2}$ ). Increasing the size of $R^{3}$-substituent at alkyne terminus led to the formation of the corresponding 1,3-diene as single isomers $2 Z, 4 E-3 \mathbf{i}\left(R^{3}=t\right.$ $\mathrm{Bu})$ and $2 Z, 4 Z-3 \mathbf{j}\left(\mathrm{R}^{3}=\mathrm{TMS}\right)$. Due to the steric congestion, compounds $3 \mathbf{i}-\mathbf{j}$ were obtained in lower yields $(40 \%$ and $47 \%$, respectively), even when using a higher catalysts loading. The use of an alkenyl substituted enynone enabled the synthesis of the corresponding conjugated 1,3,5-triene $3 \mathbf{k}$ in a moderate $52 \%$ yield. Variations of $R^{1}$ and $R^{2}$ substituents in the enynone were also accomplished as demonstrated with the preparation of 1,3dienes $\mathbf{3} \mathbf{I}$ and $\mathbf{3} \mathbf{m},{ }^{[13]}$ which were obtained in decent yields. ${ }^{[14]}$ Modifications on the vinyl diazo coupling partner proved to have a strong influence on the reaction outcome. When employing tert-butyl (2b, 5.0 equiv.) or benzyl 2-diazobut-3-enoate (2c, 3.0 equiv.) with enynone 1a, the expected 1,3-dienes 3 n-o were obtained in $78 \%$ and $71 \%$ isolated yield, respectively. ${ }^{[15]}$ It should be noticed that in particular cases (see Table 1, footnote [C]), the use of 5.0 equivalents of the diazo compound were employed to achieve better results in terms of yield and/or selectivity. The influence of the substitution at positions $\beta$ and $\gamma$ in the vinyl diazo compound was also assessed (Scheme 3). Thus, the use of enynone 1a along with $\beta$-methyl-substituted diazo compound $\mathbf{2 d}$, under otherwise identical reaction conditions, resulted in the formation of cyclopropyl diazo compound 4 in moderate yield $(56 \%$, d.r. $=1.6: 1)$. Moreover, heating a mixture of 1 a with $\gamma$-substituted diazo compound $\mathbf{2 e}$ at $70{ }^{\circ} \mathrm{C}$ in 1,2-dichloroethane (DCE), led to the formation of $\mathrm{N}$ alkylated pyrazole 5 in $44 \%$ yield.
Table 1. Synthesis of dienoates $3 \mathbf{a}-\mathbf{n}$ by zinc-catalyzed cross-coupling reactions of enynones 1 with vinyl diazo compounds 2 : Scope. ${ }^{[a]}$

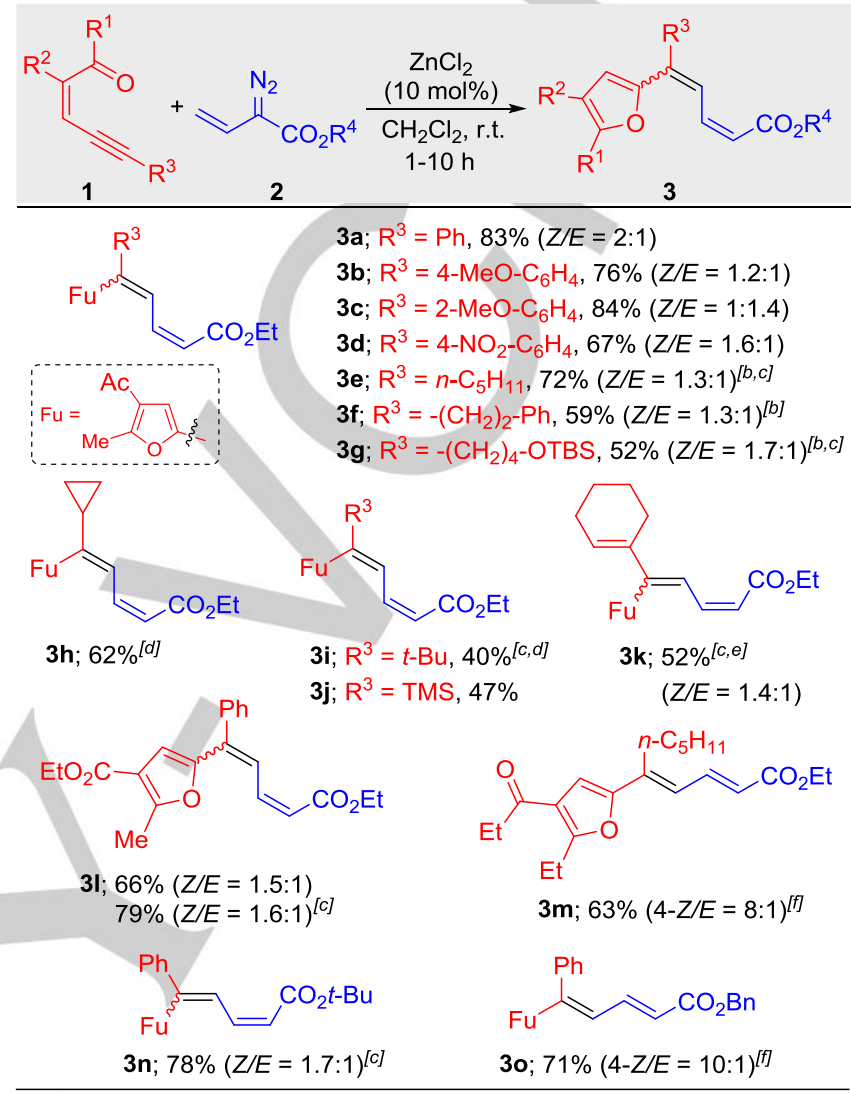

[a] Reaction conditions: 1 ( $0.2 \mathrm{mmol}), 2$ (1.0 mmol, 3.0 equiv.), $\mathrm{ZnCl}_{2}$ (10 mol\%), $\mathrm{CH}_{2} \mathrm{Cl}_{2}(0.1 \mathrm{M})$, r.t. (1-10 h). Isolated yields. $\mathrm{Z} / \mathrm{E}$ ratios determined by ${ }^{1} \mathrm{H} \mathrm{NMR}$ ${ }^{[b]}$ Separable isomers. ${ }^{[c]}$ With 5.0 equiv. of $2 .{ }^{[d]}$ With $20 \mathrm{~mol}^{\circ} \mathrm{ZnCl}_{2}{ }^{\left[{ }^{[e]}\right.} \mathrm{NMR}$ yield. ${ }^{[f]}$ After isomerization with $\mathrm{I}_{2}(10 \mathrm{~mol} \%)$. (TBS = tert-butyldimethylsilyl).

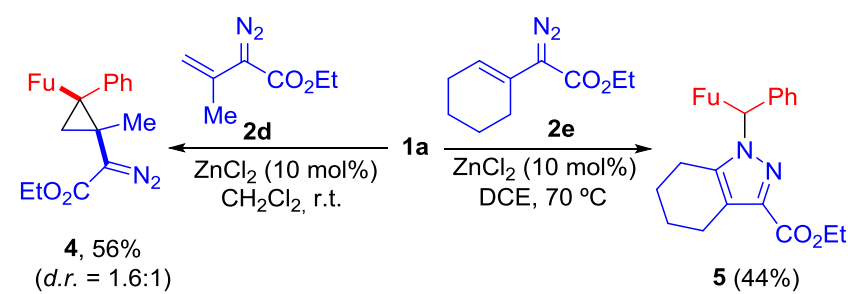

Scheme 3. Reactivity of $\beta$ - and $\gamma$-substituted vinyl diazo compounds 2 d-e with enynone 1a. (NMR yields).

A tentative mechanism for the formation of dienoates 3a-n is shown in Scheme 4. First, a 5-exo-dig cyclization of the enynone 1 generates zinc carbene species I. $^{[5 a]}$ Subsequently, a vinylogous nucleophilic attack of the $\gamma$-carbon of vinyl diazo compound 2 onto the electrophilic carbene would generate intermediate II. ${ }^{[10]}$ Then, a $1,5-\mathrm{H}$ shift might account for the formation of species III, which after tautomerization would lead to intermediate IV. Finally, elimination of zinc with a concomitant 
$\mathrm{N}_{2}$-extrusion should give rise to compounds 3a-n allowing catalytic turnover. Coordination of the carbonyl group to the zinc fragment likely accounts for the almost complete $2 Z$ stereoselectivity observed. ${ }^{[16]}$

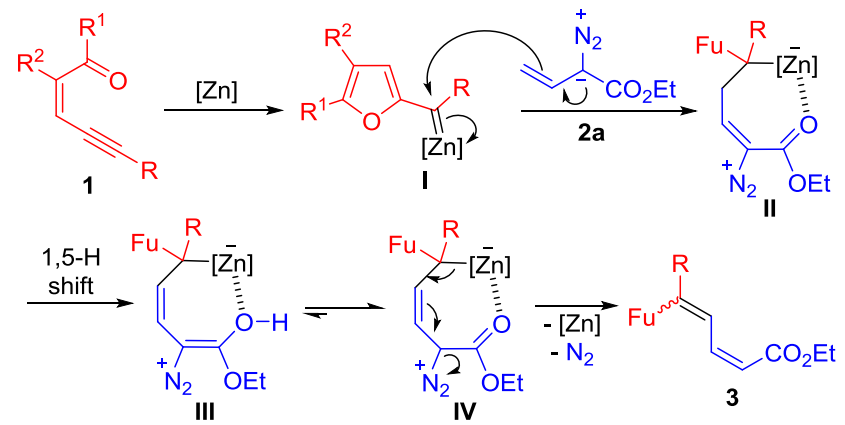

Scheme 4. Proposed mechanism for the formation of dienoates 3a-n.

It should be noticed that the connectivity of this cross-coupling seems to be linked only with the use of zinc. Indeed, transition metals capable of promoting alkene formation via carbene coupling, such as rhodium, gold or ruthenium did not afford 3a under identical conditions. Interestingly, a complementary reactivity was observed in the reaction of enynone $1 \mathrm{e}$ with $2 \mathrm{a}$ when using $\mathrm{ZnCl}_{2}$ or $\left[\mathrm{Cu}(\mathrm{MeCN})_{4}\right]\left[\mathrm{BF}_{4}\right]$, as the later led to the formation of cyclobutene 6 in moderate yield (Scheme 5). ${ }^{[17]}$

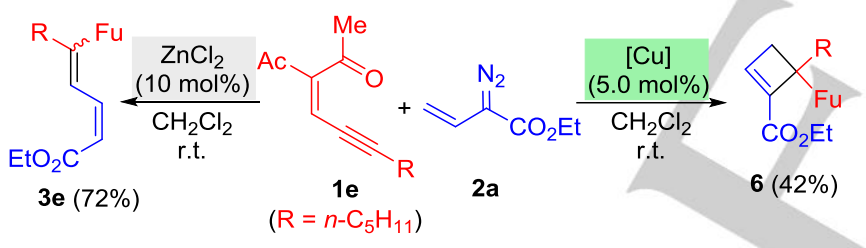

Scheme 5. Orthogonal reactivity by catalyst control. $\left([\mathrm{Cu}]=\left[\mathrm{Cu}(\mathrm{MeCN})_{4}\right]\left[\mathrm{BF}_{4}\right]\right)$

As described in Table 1, the dienyl moiety of compounds 3 comprises a $1 \mathrm{C}+3 \mathrm{C}$-coupling, being zinc carbene species I (generated from enynones 1) the 1C-fragment and vinyl diazo compounds 2 the 3C-partner. As a complementary synthetic route towards compounds 3 , we reasoned that a commutative $3 \mathrm{C}+1 \mathrm{C}$-coupling might also be feasible by using a vinyl zinc carbene species (3C) and simple stabilized diazo compounds (1C) as coupling reagents (Scheme 6). This hypothesis relied on our recently described method to generate zinc vinyl carbene intermediates from cyclopropenes. ${ }^{[18]}$

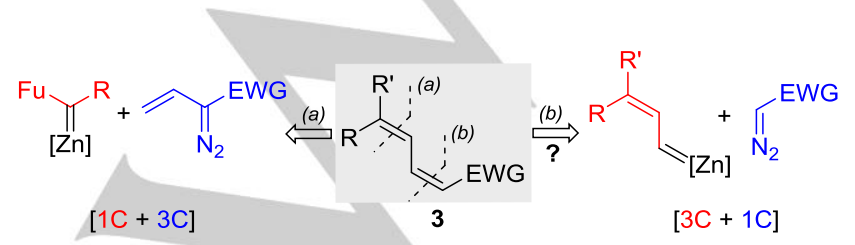

Scheme 6. Commutative approaches to 1,3-dienoates 3 by means of zinccarbenes and diazo compound couplings.

Subsequently, we evaluated the feasibility of this different approach. Gratifyingly, we found that simple $\mathrm{ZnCl}_{2}$ was a competent catalyst to promote efficiently this $\mathrm{C}-\mathrm{C}$-coupling under mild reaction conditions ( $10 \mathrm{~mol} \%$ of $\mathrm{ZnCl}_{2}, \mathrm{CH}_{2} \mathrm{Cl}_{2}$, r.t.) as shown in Table $2{ }^{[19]}$ In this manner, the use of symmetrical 3,3-dialkylcyclopropenes along with ethyl diazo acetate (8a, 3.0 equiv.) enabled the preparation of dienoates $3 p-r$ in very good yields (75-86\%) and moderate 2Z-selectivity. Unsymmetrical 3adamantyl-3-methylcyclopropene led to diene derivative $3 \mathrm{~s}$ in excellent yield (95\%) as 2Z:2E mixture (2:1). As expected, 3methyl-3-nonyl cyclopropene afforded $3 \mathbf{t}$ in good yield $\left(82 \%{ }^{1} \mathrm{H}\right.$ NMR) but as mixture of 4 isomers. ${ }^{[20]}$ Moreover, other diazo compounds bearing different electron-withdrawing substituents, including ketones, could be employed for the synthesis of compounds $3 \mathbf{u}-\mathbf{w}$ in a similar high efficiency $(85-96 \%) .{ }^{[21]}$

Table 2. Synthesis of dienoates $3 p-\mathbf{v}$ by zinc-catalyzed cross-coupling reactions of cyclopropenes 7 with diazo compounds 8 : Scope. ${ }^{[a]}$
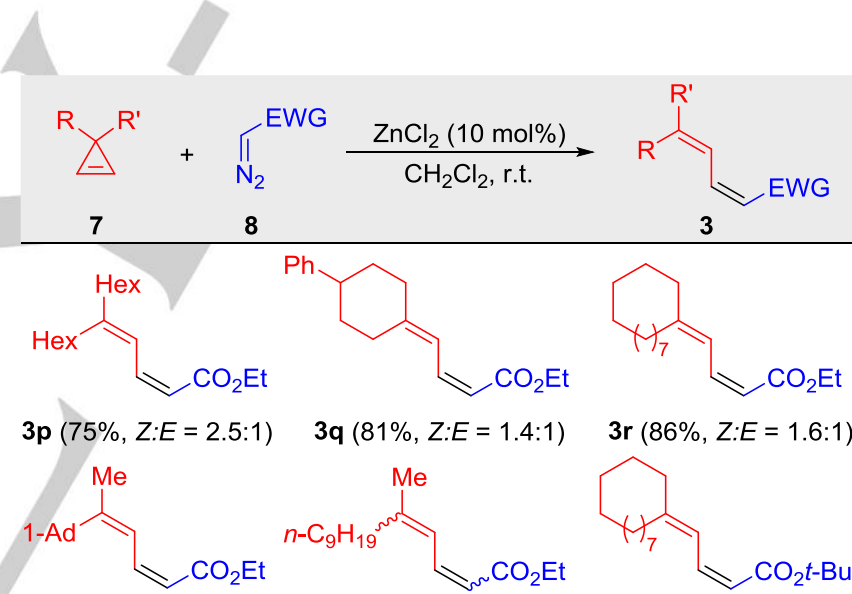

3s $(94 \%, Z: E=2: 1) \quad 3 t(75 \%, 4: 2: 2: 1)^{[b]} \quad$ 3u $(96 \%, Z: E=1.5: 1)$<smiles>CC(=O)/C=C\C=C1CCCC1</smiles>

[a] Reaction conditions: 8 (0.2 mmol), 8 (0.6 mmol, 3.0 equiv.), $\mathrm{ZnCl}_{2}$ (10 mol\%), $\mathrm{CH}_{2} \mathrm{Cl}_{2}(0.1 \mathrm{M})$, r.t. $(1-5 \mathrm{~h})$. Yields of isolated products. Z/E ratios were determined by ${ }^{1} \mathrm{H}$ NMR. ${ }^{[b]}$ See the Supporting Information for isomer assignment. ( $\mathrm{Ad}=$ adamantyl).

A mechanism accounting for the later coupling should start with the in-situ generation of zinc vinyl carbene $\mathbf{V}$ by cyclopropene activation (Scheme 7). ${ }^{[18]}$ Then, a nucleophilic attack of the diazo compound onto $\mathbf{V}$, followed by elimination of zinc and $\mathrm{N}_{2}$, accounts for the formation of compounds $3 p-w^{[22]}$ 


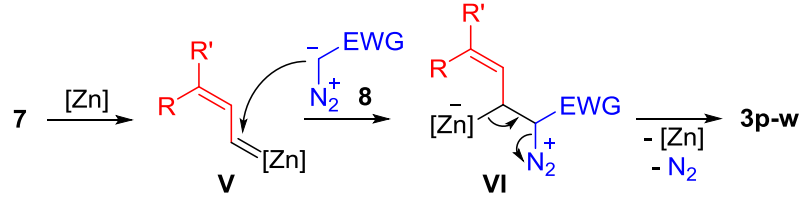

Scheme 7. Proposed mechanism for the formation of dienoates 3p-w.

In summary, we have herein reported the selective intermolecular cross-coupling of vinyl diazo compounds with insitu generated zinc carbenes from enynones. Particularly, the reaction takes place at $\gamma$-position of the vinyl diazo compound, enabling the synthesis of valuable dienoate derivatives. ${ }^{[2]}$ This kind of selectivity has not been previously reported to the best of our knowledge. A complementary approach for the preparation of dienoates based on the coupling of zinc vinyl carbenes generated from cyclopropenes and simple diazo compounds is also disclosed. Remarkably, within the context of sustainable chemistry, these transformation were accomplished with inexpensive, low-toxic $\mathrm{ZnCl}_{2}$ as the catalyst.

\section{Acknowledgements}

Financial support from Ministerio de Economía y Competitividad (MINECO, CTQ2013-41511-P and CTQ2016-76840) and Principado de Asturias (GRUPIN14-013 and Severo Ochoa PhD grant for S. M.) is gratefully acknowledged. R. V. is a Ramón y Cajal fellow. We thank Prof. J. M. González for his support.

Keywords: carbenes $\cdot$ cross-coupling $\bullet$ dienes $\cdot$ enynones $\bullet$ zinc catalysis

[1] For an early example, see: C. Grundmann, Justus Liebings Anal. Chem 1938, 29, 536

[2] For examples of intramolecular diazo cross-couplings, see: a) J. Font, F. Serratosa, J. Valls, J. Chem. Soc. D, 1970, 721; b) S. Kulkowit, M. A. McKervey, J. Chem. Soc., Chem. Commun. 1978, 1069; c) M. P. Doyle, W. Hu, I. M. Phillips, A. G. H. Wee, Org. Lett. 2000, 2, 1777; d) G.-Y. Li, C.-M. Che, Org. Lett. 2004, 6, 162; e) D. M. Hodgson, D. Angrisha, Chem. Commun. 2005, 4902; f) Y. Xia, Z. Liu, Q. Xiao, P. Qu, R. Ge, Y. Zhang, J. Wang, Angew. Chem. Int. Ed. 2012, 51, 5714; g) C. Zhu, G. Xu, K. Liu, L. Qiu, S. Penga, J. Sun, Chem. Commun. 2015, 12768.

[3] For examples of selective intermolecular diazo cross-coupling, see: a) J. H. Hansen, B. T. Parr, P. Pelphrey, Q. Jin, J. Austbach, H. M. L. Davies, Angew. Chem. Int. Ed. 2011, 50, 2544; b) Z. Zhang, G. Xu, D. Ding, C. Zhu, J. Li, J. Sun, Angew. Chem. Int. Ed. 2014, 53, 11070. For low selective cross-coupling reactions with diazo compounds, see: c) D. M. Hodgson, D. Angrish, Chem. Eur. J. 2007, 13, 3470; d) I. Rivilla, W. M. C. Sameera, E. Álvarez, M. M. Díaz-Requejo, F. Maseras, P. J. Pérez, Dalton Trans. 2013, 42, 4132; e) Z. Zhu, X. Xu, D. Ding, L. Qiu, J. Sun, Org. Lett. 2015, 17, 4244. See also: f) J. Barluenga, L. Riesgo, L. A. López, E. Rubio, M. Tomás, Angew. Chem. Int. Ed. 2009, 48, 7569.

[4] a) J. Barluenga, L. A. López, O. Lober, M. Tomás, S. García-Granda, C. Alvarez-Rúa, J. Borge, Angew. Chem. Int. Ed. 2001, 40, 3392; b) J. Barluenga, P. Barrio, R. Vicente, L. A. López, M. Tomás, J. Organomet. Chem. 2004, 689, 3793; c) J. Barluenga, L. Riesgo, R. Vicente, L. A. López, M. Tomás, J. Am. Chem. Soc. 2008, 130, 13528; d) C. VovardLe Bray, S. Dérien, P. H. Dixneuf, Angew. Chem. Int. Ed. 2009, 48,
1439. See also: e) S. Moulin, H. Zhang, S Raju, C. Bruneau, S. Dérien, Chem. Eur. J. 2013, 19, 3292.

[5] a) R. Vicente, J. González, L. Riesgo, J. González, L. A. López, Angew. Chem. Int. Ed. 2012, 51, 8063; b) M. J. González, L. A. López, R. Vicente, Org. Lett. 2014, 16, 5780; c) S. Mata, L. A. López, R. Vicente, Chem. Eur. J. 2015, 21, 8998; d) S. Mata, J. González, R. Vicente, L. A. López, Eur. J. Org. Chem. 2016, 2681.

[6] For remarkable exceptions, see: a) N. V. Kulkarni, C. Dash, N. B. Jayaratna, S. G. Ridlen, S. K. Khani, A. Das, X. Kou, M. Yousufuddin, T. R. Cundari, H. V. R. Dias, Inorg. Chem. 2015, 54, 11043; b) Y. Deng, C. Jing, H. Arman, M. P. Doyle, Organometallics 2016, 35, 3413.

[7] For a review on the use of diazo compounds as nucleophiles, see: $Y$. Zhang, J. Wang, Chem. Commun. 2009, 5350.

[8] J. González, L. A. López, R. Vicente, Chem. Commun. 2014, 8536.

[9] a) Z. Rappoport, The Chemistry of Dienes and Polyenes, Vol. 1, Wiley, Chichester, 1997; b) Z. Rappoport, The Chemistry of Dienes and Polyenes, Vol. 2, Wiley, Chichester, 2001.

[10] For selected reactions initiated by nucleophilic attack of the vinyl diazo compound, see: a) V. V. Pagar, A. M. Jadhav, R.-S. Liu, J. Org. Chem. 2013, 78, 5711; b) J. Barluenga, G. Lonzi, L. Riesgo, M. Tomás, L. A. López, J. Am. Chem. Soc. 2011, 133, 18138.

[11] For the synthesis and relevance of dienoates, see: a) E. Negishi, Z. Huang, G. Wang, S. Mohan, C. Wang, H. Hattori, Acc. Chem. Res. 2008, 41, 1474; b) J. Le Paih, C. Vovard-Le Bray, S. Dérien, P. H. Dixneuf, J. Am. Chem. Soc. 2010, 132, 7391; c) S. Xu, W. Zou, G. Wu, H. Song, Z. He, Org. Lett. 2010, 12, 3556; d) C. Souris, F. Frébault, A. Patel, D. Audisio, K. N. Houk, N. Maulide, Org. Lett. 2013, 15, 3242; e) D. V. Vidhani, M. E. Krafft, I. V. Alabugin, Org. Lett. 2013, 15, 4462; f) P.-S. Wang, H.-C. Lin, X.-L. Zhou, L.-Z. Gong, Org. Lett. 2014, 16, 3332; g) S. E. Motika, Q. Wang, X. Ye, X. Shi, Org. Lett. 2015, 17, 290. For the synthesis of 1,3-dienylfurans, see: (h) L. Zhang, Y. Wang, C. Buckingham, J. W. Herndon, Org. Lett. 2005, 7, 1665.

[12] A small amount of $(2 E, 4 E)-3$ a isomer could be detected in the ${ }^{1} H$ NMR crude $(<5 \%)$. By-products arising from $\mathbf{2} \mathbf{a}$ were not detected. Moreover, 0.8 equivalents of pure diazo compound $\mathbf{2 a}$ (volatile and relatively unstable) were recovered by flash chromatography.

[13] Due to the difficulty for ${ }^{1} \mathrm{H}$ NMR analysis for $3 \mathrm{~m}$, the reaction crude was directly isomerized with $\mathrm{I}_{2}$.

[14] Representative compounds 3 were converted into (2E,4E)-1,3-diene derivatives by isomerization with $\mathrm{I}_{2}(10 \mathrm{~mol} \%)$.

$$
\begin{aligned}
& \frac{\mathrm{I}_{2}(10 \mathrm{~mol} \%)}{\mathrm{CH}_{2} \mathrm{Cl}_{2}, \text { r.t., } 12 \mathrm{~h}} \\
& 3 a(R=P h) \quad 3 a^{\prime}, 87 \%(2 E, 4 E / 4 Z>20: 1) \\
& \text { 3b }\left(\mathrm{R}=4-\mathrm{MeO}^{-} \mathrm{C}_{6} \mathrm{H}_{4}\right) \quad 3 \mathbf{b}^{\prime}, 99 \%(2 E, 4 E / 4 Z=5: 1)
\end{aligned}
$$$$
\text { 3e }\left(\mathrm{R}=n-\mathrm{C}_{5} \mathrm{H}_{11}\right) \quad 3 \mathbf{e}^{\prime}, 91 \%(2 E, 4 E / 4 Z>15: 1)
$$

[15] Reactions of alkyl substituted enynones with diazo compounds $\mathbf{2 b - c}$ led to the expected dienes in low yields within a complex reaction mixture.

[16] For preliminary mechanistic studies and a mechanistic rationale on the formation of compounds 4-5, see ESI. The dependence of the selectivity with respect to the excess of diazo compound is at this stage unclear.

[17] For a similar cyclobutene synthesis, see Ref. 3f. For a review on catalytic selective synthesis, see: J. Mahatthananchai, A. M. Dumas, J. W. Bode, Angew. Chem. Int. Ed. 2012, 51, 10954.

[18] M. J. González, J. González, L. A. López, R. Vicente, Angew. Chem. Int. Ed. 2015, 54, 12139

[19] For similar reactions with heterogeneous gold catalysts, see: Y. Zhou, B. G. Trewyn, R. J. Angelici, L. K. Woo, J. Am. Chem. Soc. 2009, 131, 11734.

[20] The use of vinyl diazo compound $2 \mathbf{a}$ as coupling partner led to a complex reaction mixture.

[21] Unfortunately, $\mathrm{I}_{2}$-catalyzed isomerization of $\mathbf{3 t}$ did not increase the diastereoisomeric ratio.

[22] Noteworthy, the use of $\mathrm{Zn}(\mathrm{OAc})_{2}$ as catalyst led selectively to the formation of pyridazine 9 in $60 \%$ yield (unoptimized). 


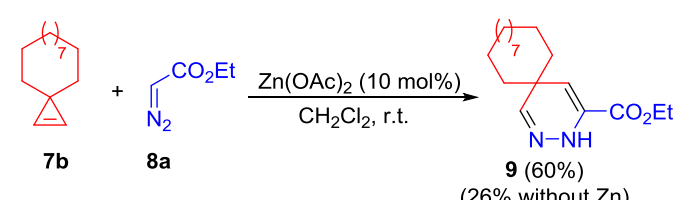

(26\% without $\mathrm{Zn})$
This compound arises from a 1,3-dipolar cycloaddition followed by a ring-expansion. Non-catalyzed 1,3-dipolar cycloadditions between diazo compounds and cyclopropenes to yield pyridazines is a wellknown process. For a review, see: M. L. Deem, Synthesis 1982, 701. 
Entry for the Table of Contents (Please choose one layout)

Layout 1:

\section{COMMUNICATION}

Zinc-catalyzed selective crosscouplings of in-situ generated zinc carbenes with diazo compounds enable the synthesis of conjugated dienoates. Coupling of enynones (furyl zinc carbene) with vinyl diazo compounds occurs with unique regioselectivity through the $\gamma$-carbon of the diazo compound. Moreover, dienoates are also prepared by crosscoupling of zinc vinyl carbenes generated from cyclopropenes and simple diazo compounds.
Sergio Mata, María J. González, Jesús González, Luis A. López* and Rubén Vicente* $^{*}$

Page No. - Page No.

Zinc-Catalyzed Synthesis of Conjugated Dienoates via Unusual Cross-Couplings of Zinc Carbenes with Diazo Compounds

Layout 2:

\section{COMMUNICATION}

((Insert TOC Graphic here))
Author(s), Corresponding Author(s)*

Page No. - Page No.

Title 